УДК 903.25-032.42

DOI 10.18411/nbg-003

\title{
ДАТИРОВКА КЛАДА ШЛИМАНА
}

\author{
Соловьев Сергей Юрьевич, \\ Москва, РФ
}

\begin{abstract}
Аннотация: Значение данной работы состоит в уточнении датировки «Клада Шлимана», имеющего без всякого сомнения всемирное значение для мировой истории и культуры. Данная работа основывается на работах У. Тейлора, К. Блегена, Н. М. Никулиной, коллектива авторов «Археология СССР» под редакцией О. Н. Бадер, Д. А. Крайнова, М. Ф. Косарева. Новый подход основывается на исследовании знаковых археологических находок - височных дольчатых колец, встречающихся в различных регионах Евразии и Малой Азии в середине 2 тыс. до н. э. и найденных в различное время, и вследствие этого не обобщенных. Височные кольца здесь служат одним из определяющих признаков близости в культурном плане удаленных друг от друга культур. Метод изучения по височным кольцам применяется в изучении ареала расселения славянских племен и считается вполне информативным и непротиворечивым.
\end{abstract}

Ключевые слова: височные дольчатые кольца; ареал расселения; датировка; эллины; Греция; меандр; топоры-молоты; Клад Приама.

\section{THE DATING OF THE TREASURE SCHLIEMANN}

\author{
Solov'yev Sergey Yur'yevich, \\ Moscow, Russia
}

Summary: The value of this work is to clarify the Dating of «the Treasure of Schliemann» has without any doubt the global importance of world history and culture. This work is based on the works of W. Taylor, K. Blegen, N. M. Nikulina, author of «archaeology of the USSR» edited by O. N. Bader, D. A. Krainov, M. F. Kosarev. The new approach is based on the landmark study of archaeological finds-temporal lobed rings, occurring in different regions of Eurasia and Asia Minor in the mid 2nd Millennium BC and was found at different times, and may therefore not be generalized. Temporal rings here are one of the defining characteristics of intimacy in culturally distant from other cultures. Method of study on the temple rings used in the study of the area of the settlement of the Slavic tribes and is considered to be quite informative and consistent.

Keywords: spiral-shaped hair rings; resettlement area; Dating; Greeks; Greece; the meander; axe hammers; the treasure of Priam.

Ряд находок Шлимана, называемые рии городища, признаваемого развали«Клад Приама», найдены на террито- нами Трои. Артефакты были обнару- 
жены на фундаменте главного здания Акрополя Трои в период с 1873 г. по 1882 г. с перерывами. Это клады с порядковыми номерами с A по R.

Как уже считается, клад не имеет отношения к царю Трои Приаму. Он датируется 2400-2300 гг. до н. э., то есть существовал за тысячу лет до Приама. Попытаемся уточнить данную дату.

Уильям Тейлор, в своей книге «Микены и микенцы» пишет о происхождении эллинов (вернее ахейцев) [1, с. 26], что материалы и большая археологическая работа подвигли исследователей к ответу на вопрос о происхождении и отличиях тех людей, создавших микенские памятники и культуру.

Корректно ли утверждение, что микенский век положил начало эллинской культуре? В Грецию не раз и не два попадали разные народы, в том числе и в историческое время. Находки археологов показывают, что вплоть до классического периода продолжалось непрерывное развитие цивилизации.

В 1900-1800 гг. до н. э. по всей Греции начала распространяться новая керамика с характерными особенностями, известными как серые «миньянские» изделия. Название предложил Шлиман, который впервые наткнулся на нее во время раскопок в Орхомене. Он назвал ее в честь миньянского племени, которое, согласно легенде, связано с этим городом. Название оказалось неудачным, поскольку на самом деле это племя никак не ассоциируется с происхождением керамики.

Миньянскую керамику легко отличить от всех других серых изделий благодаря превосходному качеству и весьма специфической технике отделки.

Скорее всего, как утверждает Тейлор
[1, с. 26], ее принесли в Грецию представители одного из кочевых племен. В форме ваз видно сходство с металлическими изделиями, по мнению Тэйлора.

Керамические изделия, похожие на серую миньянскую керамику, найдены археологами по всей Северо-Западной Турции, они имеют отчетливо выраженные признаки керамики Трои-VI, что свидетельствует об однородном населении данной области Малой Азии в начале второго тысячелетия до н. э. и об основании шестого поселения приблизительно в XIX в. до н. э.

Практически одновременное появление похожей керамики в двух обособленных, но не очень отдаленных друг от друга территориях позволяет предположить, что и в Трою, и в Грецию вторглись одни и те же захватчики. Обычно считают, что они принесли в Грецию и одну из форм греческого языка.

Носители этой культуры пришли с востока, пройдя через северное анатолийское плато в Трою. Действительно, микенская керамика в некотором роде похожа на серые изделия с северо-востока Ирана.

Захватчики принесли с собой новые виды вооружения, прежде всего кавалерию и колесницы, сыгравшие решающую роль в том, что им удалось удержать занятые территории. Впервые кости коней были найдены в Tpoe-VI вместе с миньянскими изделиями. Возможно, волна захватчиков, проникших в Грецию, привела с собой и лошадей. Данной теории противоречит то, что и в более поздние времена перевозка лошадей по морю через проливы, разделяющие Европу и Азию, была опасной, если вообще не смертельной операцией. 
Примерно в течение двух столетий захватчики укрепили свои позиции, поглотили и интегрировали существующую культуру, увеличив собственное благосостояние и укрепив власть, чему способствовали прибрежная торговля и пиратство.

В начале XVI в. наблюдается усиливающееся влияние Крита на их культуру и, можно сказать, начинается явление, известное как век Микен. Государства микенского типа, подобные описанному в «Илиаде», начали образовываться в Афинах (хотя и не очень значительно), а также в Аттике.

Сильнее всего власть Микен проявилась в Пелопоннесе, где Пилос управлял Мессенией, а также в группе крепостей в Арголиде, зависимых от Микен. Лежавшая между двумя этими территориями Лакония практически не исследована и ее микенская столица еще не открыта [1, с. 26-27].

Итак, Тэйлор опирается на специфическую миньянскую керамику в датировке, и говорит о близости троянской и греческой (ахейской) культур.

Некоторые важнейшие элементы украшений, а именно дольчатые височные женские кольца, позволяют выдвинуть гипотезу о миграции кочевых племен из уральских степей в Малую Азию, Иран и Грецию.

Теперь перейдем к датировке Клада Шлимана, и на что опираются исследователи в датировке.

Сам клад находился в серебряном двуручном сосуде. Он состоял из более чем 10000 предметов. Больше всего в нём было золотых бусин - около 1000. Причём бусины были очень разнообразными по форме - и мелкий бисер, и тонкие трубочки, и бусинки с рас- плющенными лопастями. Когда была выполнена реконструкция нагрудной пекторали, состоявшей из этих бусинок, получилось двадцать роскошных нитей ожерелья, к нижней из которых подвешивались 47 золотых стержней, а в центре располагался один совершенно особый - с тонкими нарезками.

Также интересны своеобразные кольца, называемые височными дольчатыми кольцами, имеющие количество долей от двух до шести. Височные кольца делились по материалам находок, из золота и серебра. Интересно показать двудольчатое кольцо из Клада Шлимана, каталожный инвентарный номер Aap 132, Бз 50, П 92 F 6014 и Aap 133 Бз 49, П 91 А 6015 [2, с. 53-120].

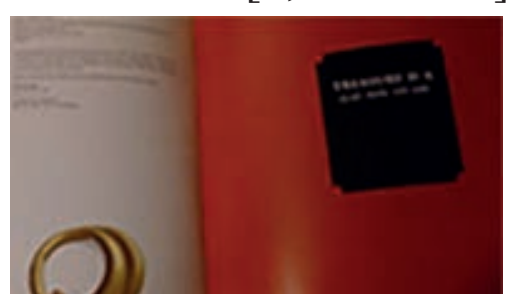

Рис. 1. Двудольчатое кольцо из золота из Собрания ГИМ (Исторический Музей)

Эти находки лишь подтверждают теорию Тейлора о продвижении пастушеских племен в Малую Азию и Грецию. Датирована находка началом второго тысячелетия до н. э.

Теперь обратимся к находкам Абашевской и Андроновской культуры. Они сложилась в лесостепной зоне Восточной Европы памятники которой находят от левобережья Днепра на западе до реки Тобол. Датируется началом-серединой 2 тыс. до н. э. Так же отличительной чертой является применение в отделке сосудов узора «меандр», а так же двудольные височные золотые кольца. На Урале, в торфяниках найдены деревянные ковши с фигурой лебедя [1, 
c. 324], похожие на хрустальный кубок из Микен того же времени (рис. 4). По материалам археологических раскопок, а так же по изображениям колесниц на сосудах видно, что люди этой культуры разводили лошадей и использовали колесницы.

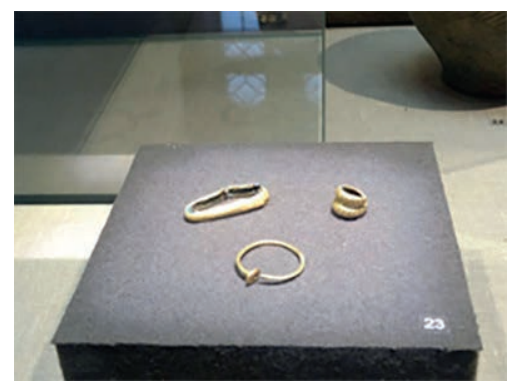

Рис. 2.

Находки в Аркаиме двудольных височных колец из золота также говорит о том, что эта культура была высокоразвита, люди обрабатывали бронзу, золото и дерево. Это было вполне культурное и технологическое общество по меркам того времени. Также они, по крайней мере, строили укрепленные пункты.

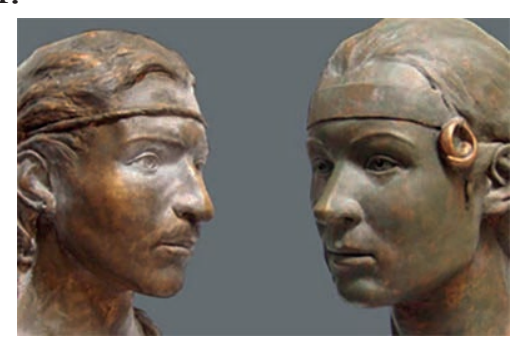

Pис. 3.

Теперь можно перейти к вопросам датировки. Височное дольчатое кольцо из России датируются концом-серединой 2 тыс. до н. э. (Оренбургская область, Абашевская Культура). Клад Шлимана из Трои датируется 2200-2400 гг. до н. э. По материалам перекрестных находок в Трое и российском Оренбуржье дата сдвигается на конец-середину 2 тыс. до н. э., (также Абашевская Культура) следовательно к эпохе Трои 6, а не Трое 2.
Почему так произошло? Из-за путаницы в датировке в фундаментах домов. Пример Рима может спутать любого археолога - многие дома 18...19 века построены на фундаментах домов 2...4 B. H. э.

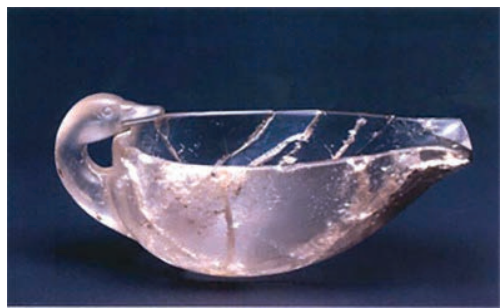

Рис. 4

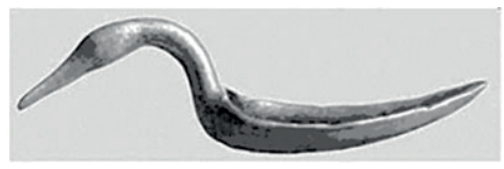

Рис. 5

Итак, сходство культур пастушеских племен лесостепной зоны Евразии и Трои прослеживается не только по керамике, но и в украшениях (височные кольца из золота, а также наборные бусы из золота, и сходство ковшей с оголовьем в виде лебедя), что опять-таки подтверждает выводы Тейлора о миграции из степей Евразии в Малую Азию, Северный Иран и Грецию.

Никулина Н. М. в своей работе [4], показывает, что троянские молоты-топоры по своему образу и содержанию, как это нетрудно увидеть, оказываются особенно близкими кругу эгейских ритуальных предметов, хотя одновременно имеют и переднеазиатские параллели (о них еще будет сказано ниже). Критские и микенские лабрисы XVI$\mathrm{XV}$ вв. до н. э. и каменные ритуальные молоты-топоры из клада L, изготовленные из нефритоида, нефрита и породы, близкой к лазуриту, выполненные в очень сложной технике, имитирующей изделия из металла (бронзы, золоче- 
ной бронзы или золота), на наш взгляд, вполне сопоставимы друг с другом. Они создают очень убедительный зрительный ряд, заставляющий задуматься о реальном хронологическом определении знаменитых троянских памятников. Наличие рядом с каменными молотами-топорами в том же кладе L нескольких наверший из горного хрусталя, совершенно аналогичных хрустальным навершиям кинжалов из микенских царских гробниц круга А, только усиливает сомнения по поводу датировки рассматриваемого археологического комплекса, обнаруживая дополнительно еще одну связующую нить с кругом памятников эгейской художественной культуры. Наличие в комплексе клада $\mathrm{L}$ спекшегося металла и сами формы мелких предметов, оказавшихся в этом конгломерате, на наш взгляд, нисколько не противоречат выдвинутой нами более поздней датировке всего клада $\mathrm{L}$ в целом (гвоздики и другие предметы подобной формы есть и во 2 тыс. до н.э.). Половина железного навершия (железный шлак), обнаруженная в том же комплексе клада L, является, кажется, только лишним подтверждением верности нашего определения. Ссылка на А. Гетце, считавшего, что бусины, спекшийся металл и железный шлак могли и не быть связаны с данным кладом, не слишком убедительна, тем более, что и по поводу самих ритуальных молотов-топоров Гетце высказался довольно неопределенно. На наш взгляд, все эти предметы все-таки относились к данному кладу, и никаких противоречий здесь не возникает. В итоге, исходя из технологического анализа рассмотренных троянских памятников, с еще большей отчетливостью вырисовывается поздняя датировка клада $\mathrm{L}-2$ тыс. до н. э. (1700-1500 гг. до н. э.) [4, с. 218].

Карл Блеген, в своей книге «Троя и троянцы» говорит о ритуальных каменных топорах из Трои: «Больше всего оно похоже на оружие бывшее в ходу в Бессарабии» [5, с. 91] (имеется в виду знаменитый Бородинский клад). Датируется Бородинский Клад примерно серединой 2 тыс. до н. э., что примерно совпадает с памятниками Абашевской культуры.

То есть, Никулина Н. М. также относит время, по крайней мере изготовления клада, к времени Трои 6.

И тогда, как это не печально для скептиков, Шлиман все-таки нашел Клад царя Приама. По крайней мере, его можно отнести к эпохе Троянской войны.

\section{СПИСОК ЛИТЕРАТУРЫ}

1. Тейлор У. Микенцы. Подданные царя Миноса. - М. : Центрполиграф, 2003. 236 c.

2. Каталог «Сокровища Трои» ГМИИ. - Милан : 1996. - 240 с.

3. Эпоха бронзы лесной полосы СССР / Отв. ред. О. Н. Бадер, Д. А. Крайнов, М. Ф. Косарев. - М. : Наука, 1987. - 472 с.

4. Никулина Н. M. Ритуальные молоты-топоры троянского клада L (к вопросу о датировке данного археологического комплекса) // Вестник Древней истории. - 1999. - № 2. - С. 218-228.

5. Блеген К. Троя и троянцы. Боги и герои города-призрака. - М. : Центрполи- 
граф, 2004. - 363 с.

\section{REFERENCES}

1. Teylor U. Mikentsy. Poddannye tsarya Minosa. - M. : Tsentrpoligraf, 2003. - $236 \mathrm{~s}$.

2. Katalog «Sokrovishcha Troi» GMII. - Milan : 1996. - 240 s.

3. Epokha bronzy lesnoy polosy SSSR / Otv. red. O. N. Bader, D. A. Kraynov, M. F. Kosarev. - M. : Nauka, 1987. - 472 s.

4. Nikulina N. M. Ritual'nye moloty-topory troyanskogo klada L (k voprosu o datirovke dannogo arkheologicheskogo kompleksa) // Vestnik Drevney istorii. - 1999. - № 2. - S. 218-228.

5. Blegen K. Troya i troyantsy. Bogi i geroi goroda-prizraka. - M. : Tsentrpoligraf, 2004. $-363 \mathrm{~s}$.

Материал поступил в редакцию 21.03.2017

(C) Соловьев С. Ю., 2017 